\title{
Stories of Adoration and Agony: The Entanglement of Struggles for Recognition, Emotions and Institutional Work ${ }^{1}$
}

\author{
Dr. Gabriele Faßauer \\ Technische Universität Dresden \\ Professur BWL, insbes. Organisation \\ Helmholtzstr. 10, 01069 Dresden \\ Telefon: $0351 / 46339009$ \\ Email: gabriele.fassauer@mailbox.tu-dresden.de \\ Jun.-Prof. Dr. Ronald Hartz \\ Technische Universität Chemnitz \\ Juniorprofessur Europäisches Management \\ Thüringer Weg 7, 09126 Chemnitz \\ Telefon: 0371 / 531 - 36677 \\ Email: ronald.hartz@wirtschaft.tuchemnitz.de
}

${ }^{1}$ Draft version - please do not quote without permission. Forthcoming in: zfbf Schmalenbachs Zeitschrift für betriebswirtschaftliche Forschung - Schmalenbach Business Review. 


\title{
Stories of Adoration and Agony: The Entanglement of Struggles for Recognition, Emotions and Institutional Work
}

\begin{abstract}
In research on organizations, the institutional work perspective plays a pivotal role in elaborating on the various instances of agency that aim to create, maintain, and disrupt institutional orders. However, the particular effects of emotions on processes of institutional work have been rarely addressed so far. In this paper, we focus on the emotions as an ambivalent driver of institutional work. We do this by introducing Axel Honneth's sociophilosophical approach on 'struggles for recognition'. In particular, we analyze how emotions trigger institutional work in terms of a person's entry as well as non-entry into struggles for recognition. For this, we suggest an analytical framework which focuses on seductive as well as agonizing aspects of relations of mutual recognition. We give evidence to our approach by an exploration of autobiographical accounts of former employees of investment banks, published in the context of the global financial crisis.
\end{abstract}

\section{Keywords}

Emotions, institutional work, recognition, struggle

\section{Introduction}

Concerned with the purposive actions through which institutions are created, maintained, and disrupted, the concept of institutional work now plays a prominent role in research on organizations (Lawrence and Suddaby (2006); Lawrence, Suddaby, and Leca (2009; 2011)). While particularly interested in the 'lived experiences of organizational actors' and various instances of agency that aim to affect the institutional order (Lawrence et al. $(2011,52)$ ), systematic attempts to incorporate emotions in studies of institutional work are still in the early stages (Creed, DeJordy, and Lok (2010); Creed, Hudson, Okhuysen, and Smith-Crowe (2014); Voronov and Vince (2012)). Recent contributions in this field explore the emotional experiences of identity work and attempts of 'identity reconciliation' of persons who respond to institutional contradictions and marginalization (Creed et al. (2010)), the emotional forces of social bonds and mechanisms of shame (Creed et al. (2014)), as well as the interplay and institutional effects of emotional and cognitive investments in current institutional orders 
(Voronov and Vince (2012)). In our paper, we contribute to this field of research by looking at 'struggles for recognition' (Honneth (1996)) as a driver of institutional work.

Recognition, generally understood as a positive evaluative response to a person's behaviors, actions, and identities (Sayer (2005)), has been rarely given center stage in the analysis of institutional work. However, in recent organizational studies, it has been acknowledged as a dimension of social interaction that basically informs identity-building and people's corresponding self-respect (Grover (2013); Sayer (2007)). While describing a positive relation to one self's identity, self-respect is derived from 'a feeling that one is living a worthwhile life and a confidence in one's ability to do what one considers worthwhile' (Sayer $(2005,954))$. Depending on how others recognize a person's value, self-respect is also an 'inescapably social emotion' (Sayer $(2005,954)$ ) that is tightly linked to other emotions like fulfillment, pride, shame, anger, or guilt (Boudens (2005)). We argue that by affecting one's emotions (the 'subjective feeling states' (Ashforth and Humprey $(1995,99)$ ) of selfrespect, social recognition impacts one's behaviors, possibly resulting in change as well as maintenance of institutional arrangements (Creed at al. (2014); Ekmann (2013); Elfenbein (2007); Tomkins and Eatough (2014)). Thus, Ekman (2013) demonstrates how the 'ideological' pursuit of social recognition in intimate relationships between managers and employees might satisfy the 'hunger for validation' (Ekman $(2013,1163))$ that drives the formation of identity and thus possibly serves as a means of the mutual subjectification and perpetuation of power structures. Tomkins and Eatough (2014), in contrast, pronounce the significance of choice in people's identity work by showing that at the same time one may desire recognition for a particular identity, one might also resist respective, but 'insufficient' offers of recognition. Albeit in a different vein, Creed et al. (2014) demonstrate that 'shaming attempts' pursued by institutionalized communities that the subjects may interpret as suspension of recognition, are likely to engender conformity with institutional arrangements as well as their rejection. We want to deepen the understanding of the institutional effects of recognition. By introducing Axel Honneth's work on recognition (Honneth (1996)), we argue that the interplay between a person's desires for a particular identity (Carr (1998); Creed et al. (2010)) and institutional offers of recognition drives struggles for recognition which serve to maintain, disrupt or create institutions accordingly.

By examining institutional work from the perspective of Honneth's approach, our initial focus is on the factual struggles for recognition and their respective outcomes. We 
propose an analytical framework that specifically helps to analyze, on the one hand, the interplay of desires for identity, struggles for recognition, and respective emotions, and on the other hand, institutional order. We argue that institutional offers of recognition have a 'seductive' character (Carr $(2001,429))$, as persons are inevitably tied to relations of mutual recognition in order to build identity and self-respect (Honneth (2010)). The affirmation of identity can fabricate a feeling of security that presumably fosters the maintenance of institutional arrangements (Dukerich, Kramer, and McLean Parks (1998); Ekman (2013); Pratt (2000)). At the same time, institutional offers of recognition might scrutinize desires for identity and oppress aspirations towards individual self-realization and self-respect (Tomkins and Eatough (2014)). This 'agonizing' potential of recognition might motivate persons to engage in the disruption of institutional arrangements or even in the creation of new institutional orders (Creed et al. (2010); Voronov and Vince (2012); Weiskopf and Willmott (2013)). Between the poles of being completely seduced by offered recognition on the one end and agonized by nagging doubt on the other, there is a wide array of ambivalent feeling states that trigger behavior and action (Creed et al. (2010); Pratt (2000); Voronov and Vince (2012)). Against this backdrop, we ask for factors that move persons toward particular struggles for recognition and respective forms of institutional work.

To evaluate these factors, and to further elaborate the value of our approach, we present an explorative case study analysis of three best-selling autobiographical books of former employees of investment banks, which were published in the context of the global financial crisis (GFC). Doing this, we particularly focus on the ways in which rather dispersed and non-elite actors experience institutions and engage in institutional work, taking the spotlight away from the 'heroic' institutional entrepreneurs (Lawrence et al. $(2009,5)$ ) who are predominantly addressed in institutional research (Greenwood and Suddaby (2006); Hardy and Maguire (2008)).

Our paper contributes to an understanding of institutional work in three ways. First, we suggest, that a recognition-based perspective offers new answers to the question of what particularly causes people to be motivated to engage in various forms of institutional work apart from rational interest and 'pure' cognitive aspects (Ashforth and Humphrey (1995); Voronov and Vince (2012)). Thus, our cases indicate that the satisfaction of people's rational interests might be significant but not enough to engender enduring feelings of self-respect and motivation to maintain institutional arrangements. In contrast, though a person may 
experience feelings of disregard to institutional offers of recognition, he/she may nevertheless give the same or even more effort to maintain the institution in question as one who does regard this recognition. Secondly, and deriving from the previous statement, our analysis provides new ways for sounding possible antecedents and limits of institutional control (Lawrence (2008)). In particular, we aim to flesh out the impacts of a person's normative commitments inevitably linked with their identity and self-respect. Normative commitments inform behaviors and actions and might be a source of conformity as well as resistance towards offers of recognition and institutional order, respectively (Sayer (2005, 955)). Finally, introducing struggles for recognition as a medium of emancipation and social advancement may help to bridge the studies on institutional work with critical views of organizations (Lawrence et al. (2011, 56); Willmott (2011)). In the remainder of this paper, we first outline vital arguments of Honneth's approach on the struggle for recognition. Secondly, we introduce our case studies, site them against the backdrop of our conceptual framing, and point out methodological issues of analysis. After a condensed presentation of each case, we finally discuss the outcomes of our study.

\section{Theoretical context}

\subsection{The 'struggle for recognition'}

Being a representative of the present socio-philosophical scholarship in the tradition of the Frankfurt School, Honneth's work on recognition plays a pivotal role in theorizing on the moral grounds of social interaction (e.g., Cooke (2006); Fraser and Honneth (2003); Van den Brink and Owen (2010)). While his work is increasingly cited and referred to by proponents of organization studies too (e.g., Fleming and Spicer (2007); Grover (2013); Islam (2012, 2013)), it's application in this particular field of research is still a desideratum. In the following, we take a closer look at the fundamentals of his theory and at the different forms of recognition proposed by Honneth $(1996 ; 2010)$. In the final part of this section, we introduce our understanding of seducement and agony as central tenets of our analysis.

Honneth understands the urge toward 'self-realization' as the insistence of a person and groups of people on their claims to identity, and the call for mutual recognition necessarily associated with these claims as the general driver of ongoing social development. He pursues the goal of drafting a 'social theory with normative content', whose intention is to 'explain 
the processes of social change by referring to the normative demands that are, structurally speaking, internal to the relationships of mutual recognition' (Honneth $(1996,92)$ ). Social development thus takes place under the 'imperative of mutual recognition, because one can develop a practical relations-to-self only when one has learned to view oneself, from the normative perspective of one's partners in interaction, as their social addressee' (Honneth $(1996,92))$. This imperative forces a person into the gradual blurring of the content of mutual recognition, and therefore, into struggles for recognition, because only in this way can one express his/her claims to subjectivity socially and thus develop an identity. Thus, recognition refers to the exercise of 'moral attitudes we are mutually obliged to adopt in order to secure jointly the conditions of our personal integrity' (Honneth $(1997,28)$ ). Accordingly, relationto-self is defined as 'the consciousness or feeling that a person has of him- or herself with regard to the capabilities and rights this person enjoys' (Honneth $(1997,25))$.

Against this backdrop, social change is rooted in the factual demand for recognition of facets of one's own identity, in 'struggles for recognition' on the part of a person and social groups. With reference to social advancement, Honneth assigns particular significance to social struggles in which individual experiences of disrespect of identity are read as typical for an entire group (e.g., sexual or racial discrimination) and in such a way motivate collective demands for the expanded relations of recognition (Honneth (1996, 162)). Granting recognition can take place in a variety of forms but always mirrors the primary intention of a certain affirmation of the other (Honneth $(2010,330)$ ). When based on identity claims, these conflicts are matters of perceived exclusion and disrespect and thus are morally motivated (Honneth $(1996,131 \mathrm{ff}$.)). 'It is the disrespect of personal integrity that transforms an action or utterance into a moral injury' (Honneth $(1997,23)$ ).

\subsection{Different forms of recognition}

According to Honneth, struggles for recognition serve as the process of individual emancipation and social advancement. In this vein, he refers to recognition as follows: 1) the positive affirmation of the characteristics of a person or of social groups, 2) an 'attitude' that is realized in concrete action, 3) and a distinct phenomenon in the social world that is not a result or side-effect of an action aimed at some other goal (Honneth (2010, 329ff.)). Before entering the different forms of recognition, we may advert to the point that acceptance of recognition is contingent on the normative state of existing recognition patterns at a particular time and place. Longstanding experiences trigger the perceived credibility of recognition and 
its progressive character, pointing to already established social patterns of recognition.

Honneth refers to institutional arrangements as 'sedimented patterns of recognition' (Honneth $(2010,117)$ ) and defines them as results of a historic course of struggles for recognition. He assumes that today's Western capitalist society is characterized by a historic differentiation of 'love', 'rights', and 'solidarity' (defined below) as three forms of recognition (Honneth (1996, 92ff.)). Together, these forms constitute an institutionalized order of recognition - that is, the social-moral order of modern society and its organizations (Fraser and Honneth (2003, 162 and 177)). Consequently, the functioning and legitimation of today's work organizations are also based significantly on these sedimented patterns of recognition in society (Honneth $(2010,117))$.

'Love' is an affective form of recognition and expresses itself in emotional attention paid between persons. As people grow up, the experience of 'love' helps them acquire trust in the value of their own bodily needs and is the basis of personality formation (Honneth (1996, 95); Fraser and Honneth $(2003,163))$. 'Love' is a form of interaction characterized by the principle of mutual care and affection. The form of recognition taken by 'right' refers to the cognitive-rational respect between legally equal partners in an interaction (Honneth (1996, 107ff.)). In contrast to 'love', this form of recognition is conceptualized as universal. Thus, 'rights' are directed at general qualities and skills that pertain to all legal subjects without regard to a person's status. Through legal recognition, subjects can regard themselves as autonomous, morally responsible persons and thus feel as if they are full members of the community. The form of 'solidarity' refers to a person's social esteem. It distinguishes itself from 'rights' in that it does not refer to recognition of the person based on a legal status but by a gradual assessment of concrete qualities and skills (Honneth (1996, 121ff.)). This form of recognition is directed at the performance of the person, which is perceived in our society primarily through paid work. The recognition form 'solidarity' is thus at once an integrating and differentiating mode of recognition: It has an integrating effect because the social recognition of individual factors assumes a shared value horizon and/or common standards of judgment. Yet this recognition also has a differentiating effect, because it seeks to make individual, biographically-related differences socially visible and judge-worthy. For Honneth, 'the experience of being socially esteemed is accompanied by a felt confidence that one's achievements or abilities will be recognized as "valuable" by other members of society' (Honneth $(1996,128)$ ). 


\subsection{Seducement and agony of recognition}

In light of Honneth's arguments, we propose that recognition has a seductive as well as an agonizing potential for a person. We define offers of recognition as 'seductive' when they are perceived as promises to positively affirm a person's desire for a particular identity. For interpreting effects of recognition, the term seducement seems particularly appropriate to us, as it is more associated with notions of emotionality and less with high degrees of rationality, consciousness and negotiation (Carr (2001, 429)). Similar to the theory on social identification, we argue that organizations which are attractive or prestigious are more likely to foster such seducement than those that are not because they are able to enhance a person's self-esteem (Pratt (2000, 483)). Conversely, the agony of recognition refers to feelings of personal harm due to the ascription of identity that is negatively perceived and evaluated by addressees. The prerequisite of seducing and agonizing recognition is the concomitance of subjective significant arenas of recognition. Thus, the subjective relevance of recognition and the extent of its seducing and agonizing potential are basically interrelated with the felt value of the field of interaction or the social bonds particularly concerned (Creed et al. (2014); Grover $(2013,45))$. Thus, the agonizing potential of felt misrecognition might have an even greater weight when it is taking place in actually seductive arenas of recognition (Sayer (2005)). This way, scrutinizing one's personal significance attributed to respective arenas might be the ultimate and most-agonizing result of abiding misrecognition in that particular field of interaction.

We propose that organizations offer recognition and thus present arenas for identification. According to Honneth, modern society and its organizations are informed by institutionalized and contested patterns of recognition within the three forms of 'love', 'rights' and 'solidarity'. In organizations, these are represented, for example, in mentoring and support practices (love); legal arrangements, like working contracts (rights); as well as in wage, bonus and carrier systems (solidarity). For example, Pratt (2000) shows that the management of identification among Amway distributors is predominantly based on the moral logic of 'love', where family-like relations with the company are strongly fostered. Similar to concepts of organizational identification, we further suggest that a person can reside between the poles of seducement and agony (Kreiner and Ashfort (2004)). Such an ambivalent attitude toward offered recognition might result from the perceived gap between 
promised and factual realization of recognition, or the divergent cognitive and emotional evaluation of offered recognition (Voronov and Vince (2010)).

We argue that offers of recognition - be they perceived as seductive, agonizing or ambivalent - can foster struggles for recognition and particular forms of institutional work. Following Honneth, respective struggles would particularly aim to enforce a changed or extended kind of attention by citing the principle of mutual care and affection (love), to extend or differentiate legal arrangements by highlighting equality with others (right), or to highlight previously neglected or undervalued activities and skills in order to enforce one's higher social esteem and with it, a redistribution of resources (solidarity). Manifestations of such struggles are versatile, reaching from physical presence and violence to verbal and more subtle forms of contentions. When referring to institutional work, we propose that struggles of recognition neither necessarily disrupt nor create new institutions but may also serve to maintain institutional arrangements. For example, a person might engage in struggles for recognition specifically to belong to the particular institution in question and to fully enjoy its offers of recognition. Thus, for now and in reference to our particular cases, the assumption of an ongoing social development tends to be an open question.

\section{Methodological remarks}

\subsection{Context: The Global Financial Crisis}

Our study is situated in the context of the Global Financial Crisis (GFC). For Crouch (2011: i), the GFC was 'a major crisis for the set of economic ideas that have ruled the Western world' and consequently a crisis of the 'cognitive infrastructure' (MacKenzie $(2009,178)$ ) of the world of finance and its institutions. As Jacobs $(2012,377)$ put it, financial crises 'highlight the dark side of economic life - the corruption and bad faith, the impulsive gambling, the suffering, the injustice, and the death of corporate actors - that foregrounds urgent problems of meaning.' After the collapse of Lehman, one major feature of the public discourse about financial institutions and its protagonists was the collective image of the banquet and feast, 'marked by excess and exuberance, summed up for many in the jubilant

faces of City traders celebrating their annual and increasingly extravagant bonuses' (Gamble $(2009,3))$. Beside extensive mass media discourses and political coverage of the GFC, a considerable number of 'inside stories' and autobiographies were published. To us, an 
exploration of such accounts seems a great opportunity to elaborate the value of our approach. The analysis of autobiographies allows both an intimate view of the day-to-day practices of struggles for recognition, emotions and institutional work and of its reflection through persons once affiliated to specific financial institutions. This is in line with the observation that the crisis brought to mind the contingent nature of the economic order, its established practices, and its discourses. Thus, autobiographies in times of crisis deal with the 'urgent problems of meaning' that arise from trying to make sense of the crisis and in dealing with issues of accountability, responsibility and identity. They bridge societal events with personal accounts (Plummer (2001); Watson (2009)). This way, the analysed accounts enable us to explore 'links between people's personal circumstances and broader 'public issues', social structures, cultures and historical trends' (Watson $(2009,449)$ ). Specifically, a major crisis like the GFC offers the opportunity to investigate the particular sedimented patterns of recognition as a basal element of the social fabric of financial institutions. In drawing on autobiographies, we further follow the perspective that identity is performed through narratives and that autobiographies are the most appropriate literary genre of identity narratives in modern times (Czarniawska-Joerges (1996); Watson (2009)). Further, as Boudens $(2005,1287)$ argues, the expression of feelings and emotions is a pivotal aspect of the performance of any narrative, thus offering 'an excellent means of indirectly accessing emotions'.

Finally, to adopt Honneth's work to such a perceived 'elite place' as investment banking is promising both to explain institutional work in that specific area as well as to give evidence to the general value of the idea of recognition for explaining the social fabric. Thus, our study is a plea for the study of recognition beyond its traditional focus on social movements and societal conflicts.

\subsection{Data sources and analysis}

We draw on three bestselling autobiographical accounts, as follows: Greg Smith's 'Why I Left Goldman Sachs - A Wall Street Story', Lawrence G. McDonald's 'A Collosal Failure of Common Sense - The Inside Story of the Collapse of Lehman Brothers', and finally, the book of a female stock trader from Germany: Anne T. who wrote, 'Die Gier war grenzenlos' 
(The Greed was Limitless) $)^{2}$. The selection of cases follows the idea of the reconstruction of theory as proposed by Burawoy (1998). Thus, we choose the books to explore the institutional micro-foundation of struggles for recognition and to give evidence to our theoretical framework. All three accounts present extreme cases, as the authors deal with a major economic and institutional crisis (GFC). Consequently, the cases enable us to get insights into the social fabric of financial institutions that would be hardly possible in 'normal' times. We selected the three autobiographies due to their polar character as well (Eisenhardt (1989)), which became obvious after a first diagonal reading of six different autobiographical books published in the context of the GFC. The books of Smith and MacDonald are dominated by a serious tone and an honorable style of writing, which articulates the tone of worry over what was about to happen at Lehman and at Goldman Sachs before and throughout the crisis. In contrast, the text of Anne T. comes close to a colportage, oscillating between fascination and cynical distance while she reconstructed her occupation in an investment bank. The different style of the books seems to signal distinct patterns of recognition, emotions and institutional work.

We processed our analysis in three steps. First, we carefully read and discussed the three books within a period of three or four months. At this point, our aim was an overall capturing of their respective storylines and their descriptions of struggles and emotions in particular. In making notes and marking passages and sentences of the books, we followed the guide of a 'simple' question: 'What strikes you?' (Saldana $(2013,22))$. Second, the books were scanned and imported as PDF to NVivo 10, a qualitative research programme, so we could pursue a more fine-grained analysis. We did this on the background of three leading research questions. Thus, we asked 1) for the specific entanglement of emotions and institutional offers of recognition, 2) the interplay of emotions and struggles for recognition and 3) how do respective struggles for recognition look like. For this, we read the material, processed a first-order coding in NVivo and simultaneously reflected on and refined our coding onto the background of our reconstruction of the concept of struggles for recognition. Thus, we focused on a number of constructs that we deduced out of the conceptual discussion. In order to grasp the books' significance for a reconstruction of struggles for recognition, we compared them with our experiences while reading them. To get a comprehensive picture of

\footnotetext{
${ }^{2}$ All quotes are our own translation.
} 
these struggles, we decided to focus on the reconstruction of the expressions of emotions, descriptions of critical events, and the autobiographical turning point; we also focused on author's personal reflections of such events and turning points and their subsequent actions. This focus enabled us to identify pivotal moments of interaction, where the entanglement of institutional offers of recognition; its seductive, ambivalent or agonizing character and (changing) arenas; as well as its subsequent struggles become visible. Finally, we developed a comprehensive reconstruction of these moments - that is, a reconstruction of the stories of the three authors on the background of the concept of struggles for recognition. In the following, we will present these three stories.

\section{Findings: The three stories}

\section{1 'I felt at home' - The story of Greg Smith}

Smith resigned in 2012 as the Head of Goldman Sachs' equity-derivatives business in Europe. The resignation became public and widely discussed due to Smith's article in the New York Times titled, 'Why I Am Leaving Goldman Sachs'. Shortly afterwards, he published the best-selling book, Why I Left Goldman Sachs, where he reflected on his career at Goldman Sachs from the beginning as intern to his resignation. We reconstruct his story along different stages, critical events and struggles.

The 'boot camp'. The first stage comprises the extensive descriptions of Smith's efforts to get a job at Goldman Sachs. The first major step to get hired at Goldman Sachs was his participation at a summer internship in 2000. Smith was impressed by the offer of recognition in the form of solidarity, articulated as a promise to evaluate performance irrespective of social status. For example, one of the interns got 'absolutely grilled' (p. 1), but '[w]hat I didn't know at the time was that his dad was a billionaire and one of the most powerful financiers in the world. But this was Goldman Sachs, and it didn't matter who your dad was. You had to prove yourself like everyone else' (p. 1). To gain recognition meant surviving the hard meetings and the 'boot camp' (p. 1) atmosphere. However, Smith 'enjoyed' the internship (p. 5), because Goldman 'took its culture so seriously', to serve its clients. In his view, Goldman was not simply focused on 'tough finance questions'. At Goldman, they wanted 'to getting to know you' (p. 11). 
Beside his felt enjoyment of the culture, he was attracted by the thrilling atmosphere of the trading floor: 'For me, the exciting thing about Wall Street was the big fish, the institutions. So I signed up for Equities. I wanted the real trading floor experience: standing up in a frenetic environment, shouting across the floor. [...] Looking around, I found I loved the energy. I loved the chaos, the yelling, the tensions. [...] I desperately wanted to understand it and be part of it. [...] I felt at home' (p. 14-15). The entanglement of the 'boot camp' atmosphere, the interest of Goldman in people, and the energy on the trading floor drove Smith's struggle for recognition, that is to successfully pass the internship and to convince Goldman Sachs that he was the right person in the right place: 'I knew that I wanted to work for Goldman Sachs, but did Goldman Sachs want me?' (p. 29)

From the 'magic call' to 'a seat at the grown-ups' table' Smith received the 'magic call', that is the offer of a full-time job at Goldman, in late August 2000. He felt excited and happy. To get this job was 'the golden ticket, a dream job for anyone who wanted to start a career on Wall Street. Goldman Sachs was the best of the best - the 'Rolls-Royce of investment banking"' (p. 31).

This feeling of adoration, which stands for the seductive character of the offered recognition, was encouraged through a number of critical events. First, Smith was impressed by the company's behavior after the 9/11 attacks. For Smith, the company took care of its employees by helping them with accommodation, money, etc. throughout the weeks following 9/11: 'This was Goldman Sachs at its best. I remember thinking that when it came to efficiency, execution, and generally having its act together, Goldman Sachs was the gold standard. It had the smartest, most resourceful people; no other bank on Wall Street came close' (p. 43). Smith's proud feeling was further intensified due to his perceived care of the company for its clients during these times: 'This is where Goldman Sachs becomes Goldman Sachs. Let's be ultraattentive to our clients; let's help them get back on their feet, even if it doesn't benefit us immediately. Because that's what the clients are going to remember' (p. $45)$.

Second, Smith described his first trade as another critical event and moment of struggle at Wall Street. Smith made this advancement shortly after 9/11. It 'was a proud and happy moment' (51) accompanied with the feeling that he 'was being welcomed to the club' (p. 51). Getting more responsibility for deals and the thrilling and seductive atmosphere of the trading 
floor caught him bodily, emotionally and cognitively: 'Between 8:20 A.M. and 4:30 P.M. on that day at the end of January 2003, I ate nothing; I drank nothing. I never had time for a bathroom break. I barely noticed. I was operating at hyper-speed, all my senses engaged, 100 percent focused. It was what I imagined a Zen state might feel like' (p. 85). His adoration of the perceived company culture and the principles of Goldman Sachs (e.g., 'Our clients' interest always come first' and 'Integrity and honesty are at the heart of our business' [p. 112]) guided Smith's behavior the following years. These mottos 'were drummed into our heads when we were summer intern, and I felt idealistic about them. At one point, I pinned a copy of them next to my desk' (p. 111-112). Another critical event highlights this: the blackout in New York in August 2003. To remain in the company building 'was the right thing for us'. Because ' $[\mathrm{t}]$ he reason we stayed is ... we wanted to prove to the clients that we'd be there for them if they needed us' (p. 88). Again, performing for and representing the company in this way was a proud moment. For Smith, it indicated also his self-development throughout his first years at Goldman Sachs: 'As I walked off into the asphalt kiln that was Lower Manhattan, it occurred to me that while my own summer internship felt like five minutes ago, three years had gone by. I had just executed more than $\$ 2$ billion in futures trades in the midst of a blackout. This felt like a seat at the grown-ups' table' (p. 90).

'Welcome to the casino' From 2006 onwards, Smith perceived a change in the corporate policy of Goldman Sachs and the company culture, forced by particular line managers. For Smith, the evaluation of performance was now focused on 'numbers', that being quick returns and not on the promotion of the values of the company and its long-term interests. In his perception, this change 'was detrimental to Goldman's culture and morale' (p. 97) because 'it was all about the Benjamins now' (p. 155). Recurring feelings of discomfort, anger and a creeping alienation characterize the final years of Smith at Goldman. He recognized a growing disrespect for his performance. Recognition now meant to 'go out and find some elephants today! Let's go get the biggest trades to the tape!' (p. 96). Smith was disappointed, because for him, „Goldman really had become more like a hedge fund, concerned more with helping itself than helping clients, with doing only the business we thought could make us a lot of money and ensure our survival' (p. 154). Struggling again for recognition, he began to write market commentaries and defend and maintain the 'old culture' in trying to build up his own relationships to clients after his transition to Europe. However, ' $[\mathrm{t}]$ he problem was 
that my fans in upper management and my clients had more knowledge of the work I was doing than my direct managers, who were sitting a few seats away from me' (p. 170). Smith further agonized over the growing mistrust of clients which, for him, was a direct consequence of the cultural changes at Goldman. Working for the London office, he was shocked at how many times he heard people - both very senior and very junior - refer to their clients as 'muppets'. 'Where, I wondered, had this adversarial viewpoint come from - the idea of the client as someone much less smart than you, someone you could try to take advantage of?' (p. 220) For Smith, 'bad behavior gets rewarded' (p. 227). The crisis in Greece indicated the resulting turning point, where 'it was all too much. We had advised Greece all those years $[\ldots]$ Now that the chicken comes home to roost, we were showing hedge funds how to profit from Greece's chaos' (p. 232). Desperation and sadness characterized the months before Smith resigned: 'This was no longer the Goldman Sachs that, when I joined, young people were excited about' (p. 234).

4.2 'On the gundeck of the ship' - The story of Lawrence G. McDonald

Until 2008, McDonald was vice president of distressed debt and convertible securities trading at Lehman Brothers. In retrospect, Lehman was a 'banking warrior' a 'brilliant finance house' (p. 1). For him, looking back is always coupled with feelings and sadness and despair: 'Yet in my mind, I remember the great days. And as I come to a halt outside the building [the old headquarters in Manhattan], I know too that in the next few moments I will engulfed by sadness' (p. 1).

The 'rocky road' to Lehman McDonald described his own career before joining Lehman as a 'rocky road'. He worked as a salesman for frozen meat, dealt with investment assets for Merrill Lynch in Philadelphia and co-founded a start-up for online bond-trading, which was finally sold to Morgan Stanley. In 2004, he went to Lehman. In reflecting on his career from the beginning, McDonald ascribed himself with a 'killer work ethic' (p. 29). Thus, to work at Wall Street seemed to promise a thrilling and tough experience, which he desperately wanted from the beginning of his career. Describing his struggle for recognition, he stated, 'In my secret thoughts I set myself a five-year target to make Wall Street - not some plush carpeted office, but right down there in the Colloseum of the trading floor, where the rubber 
meets the road, where the toughest characters in the game stand guard over the firm's capital' (p. 17).

The description of entering Lehman is overtly driven by a feeling of adoration: 'I walked the hallowed floors of this bank, and it's still difficult for me to explain what it meant on that first morning. I knew the place had made a twenty-first-century move from its famous old headquarters in the financial district, but so far as I was concerned it was like moving a cathedral. The real estate was different, but the holiness remained' (p. 84). For McDonald, to 'work for Lehman was like a dream that becomes reality' and to become a part of ' 120 years of excellence' (p. 82). This adoration was quickly dampened by the perception of distance and struggle between the top-management of Lehman, namely Richard Fuld and Joe Gregory, and the day-to-day businesses on the trading floor where McDonald worked. More precisely, it was on the trading floor where McDonald saw the spirit of Wall Street and Lehman alive. There was the atmosphere of thrill and toughness where he wanted to belong too. In contrast, Richard Fuld and Joe Gregory were perceived as the greedy 'men in the ivory tower'. Looking up from the third floor to the thirty-first was constantly accompanied by anger and disappointment: 'Down where I worked, on the gundeck of the ship, where financial cannons roared and real people found themselves in the thick of the battle, I never once heard the name Joe Gregory as a possible commanding officer if Fuld ever decided to retire. [...] Joe was mostly closeted with Fuld up there on the thirty-first floor. In the coming years, I would constantly hear of their scheming to keep Lehman's stock prices high, quietly obscuring bad news, loudly announcing good news, gathering vast mountains of shares for themselves' (p. 98).

Similar to Smith, McDonald wanted to get recognized for his work on the trading floor, which seemed to be based on 'pure' performance. Wrong deals were critical events in that case. After his first 'wrong trade' a managing director joined his desk and shouted at him: 'McDonald, we only hire the very best people here. And the best don't fuck it up. You want to be one of us, don't fuck it up again. Ever. Hear me?' (p. 105) For McDonald, the managing director 'was right' (p. 105). To belong to the best and to survive at the trading floor, you need to follow the principle of zero tolerance and accuracy. Conforming to this "was demanding, it was all hell about six times a day, and it was hard. Real hard. And it was the hard that made it great' (p. 105). 
'A house divided against itself cannot stand' In the eyes of McDonald, the years from 2004 onwards were a time of accelerated decline of Lehman. In his view, this was caused by wrong management decisions and the inability of top-management. The years were shadowed by a growing anger, coupled with rising efforts of McDonald and his colleagues on the trading floor to keep Lehman alive. For example, in recognizing problems at the housing market, McDonald and his colleagues tried to influence the top-management: „Back at the factory, I had a team of analysts burning the midnight oil, poring over charts and statistics, locating photographs and converting them into slides. Larry and I were preparing the mother of all presentations, to convince the top Lehman executives that this ship must swerve away from the course set by Dick Fuld and Joe Gregory, who had not personally been on the bridge for about five years' (p. 217). However, Fuld and Gregory did not listen. Instead, McDonald perceived the layoff of people who stood close to the traditions of Lehman in terms of integrity and trust. McDonald and his colleagues recognized themselves as the 'last man standing' on the aura and reputation of Lehman.

This perceived disrespect culminated in the event of the so-called 'bonus debacle' in 2007. Whereas the people on the trading floor were affected by a bonus-cut, Fuld and Gregory paid themselves the largest bonus either of them ever received: 'It was, however, perfectly obvious that the two leaders had nothing but contempt for us. And when they sat down to work out the bonuses, they screwed us all' (p. 274). Whereas the 3rd floor fought for Lehman, Fuld and Gregory 'had decided to make themselves so rich that it wouldn't matter to them whether the ship survived or not' (p. 274). So, 'the rest of us, devalued, demoralized, and generally pissed off at the bonus-cutting treatment they had leveled at us we who had tried so hard - also made our separate ways home' (p. 275).

Finally, McDonald was laid off in March 2008 in the context of a mass layoff. For him, one reason for the layoff was his 'close association with a different era' (p. 280). In retrospect, he was proud of the battle he fought, even though it was finally lost: 'Lehman Brothers, where I had reached the holy grail, where I had fought it out on the trading floor with the best in the business. I was just so proud of it. I was proud of the people I had known. And I was proud of our many triumphs. I had loved every minute of my time there. I was proud of my achievements, and when I thought of them, somehow this bad day didn't matter. I'd been there. I'd made it to the top' (p. 281). 
4.3 'It's me, the queen of money' - The Story of Anne T.

Anne T. is the pseudonym of a derivative saleswoman, who worked from 2000 until 2008 for a German bank. She decided to leave before the crash in 2008. In 2009, she published her book about her years as a saleswoman, which was recognized as the first 'insider-report' about the trading scene in Frankfurt (Main). For Anne T., her decision to resign was caused by 'sickness' of the business, where 'bankers ... put their love for money above everything else' (p. 7).

Crossing borders and entering the trading floor For Anne T., the desire to go into finance was driven by the efforts to distinguish herself from the traditional values of her parents. She saw herself as a member of a generation who 'wanted to cross borders, to meet the challenge and wanted to make everything better, faster and more exciting than our parents did' (p. 15). The founders of the New Economy in Germany functioned as a role model. It was their success in combination with a cool and rebellious attitude that fascinated her. There was a 'gold-rush mood' (p. 17) and she 'wanted to join the party, to be a huntress, to have fun' (p. 17). Internships in Frankfurt and London reassured her. She was impressed by this 'quite cool world', where she 'was surrounded by extremely smart people that were in a good mood and easily made heaps of cash' (p. 20). To 'join the party' she applied to a German bank and was brought in for an assessment. She liked the 'unorthodox behavior' during the interview and was sure, in terms of the conceivable struggles, that 'to pull no punches' (p. 37) should not discourage her.

Anne T's description of the trading floor differed from that of Smith and McDonald in her recognition of gender aspects. In her perception, she joined a male-dominated and machismo culture. Facing this, she asked herself: 'But why should we not be as ambitious and assertive and work as hard as men? Were we not even better?' (p. 45) It seemed necessary to be cool and tough ,to be accepted by this men club' (p. 47). Getting the desired recognition was bound to the successful handling of her first trade. In her perception, everyone on the floor seemed adverse to her. To get the deal right 'was an adventure like I've experienced never before. The adrenaline released by my body would normal office workers not achieve within a year.' (p. 51). Finally, she passed her 'baptism by fire' when she was accepted by colleagues for showing fast reactions and coolness. Now ' $[t]$ here was a chance for me to 
belong to this club of millionaires' (p. 55).

In it for the money To work on the trading floor and to make deals with clients was about 'earning money'. Thus, '[i]f there were certain things necessary to do [in order to earn money], then they would go to any length' (p. 46). Thus, getting recognized by her male colleagues depended on making big deals and participating in the success of 'creative financial products'. In a cynically aloof way, she stated: 'The one who was at the top of the P-and-L-list [profit-and-loss report] was convinced that he had the longest dick in the world, he was a Big Swinging Dick which was reported all the time. P-and-L, that was a real menthing. For them, it was synonymous with their ego. Their self-confidence staggered to the same extent [as their] own P-and-L' (p. 73). However, that was the game she wanted to play, and 'like all my colleagues, I was infected by a virus, called money' (p. 105). Thus, internal risk management and supervision are more or less troublesome things. The respective staff 'were annoying little assholes who always snoop around' (p. 176).

Against this backdrop, moments of discomfort or doubt were hardly identifiable. In contrast, Anne T. retrospectively identified a growing cynicism, which seemed to become the dominant mood when deals were made in the context of such critical events as $9 / 11$, the war in Iraq or more generally in reflecting the trust of clients: 'It was Grassmann's [an important client] job to identify these risks, not our job to point them out' (p. 196). In this way, the perceived naiveté of the clients surprised and more and more disgusted her. The resulting disrespect for the clients turned the initial thrill of making deals into a more or less boring and charmless activity.

Finally, Anne T, experienced a kind of rude awakening. It seemed that the cynical distance to the given recognition turned to an overall reflection of the behavior of her colleagues and peers. She recognized herself as one of 'these drilled dolls' (p. 209) and that her colleagues looked like 'marionettes' (p. 208). During a meeting, she suddenly asked herself questions that she hadn't asked before: 'What am I actually doing here? What do I want here? Why do I have to talk to these disgusting men?' (p. 209). She resigned and refused the offer of (more) money: '"What do you want? How much more do you want to have?" He didn't consider the idea that I really wanted to leave. It was a current strategy in trade areas to negotiate more money when the letter of dismissal was already signed. It's a tough business. "I don't want more money", I answered. "I want nothing anymore". I left the bank 
with a smile. I was out. A good feeling' (p. 216).

\section{Discussion}

Our reconstruction of the three stories reveals differences in patterns of recognition and its perception by the authors of the books. Further, different patterns of emotions and struggles become visible. In the following, we will highlight some of these differences at first and afterwards discuss two particular contributions to the study of institutional work.

In a nutshell, the story of Smith shows a strong adoration of the handed-down company principles which guided his actions throughout his time at Goldman. His struggles for recognition during his internship and his efforts to conserve the company principles give evidence to this. Whereas in his first years at Goldman, the feeling of pride was dominant, it turned to discomfort, disappointment and alienation. This change was accompanied by a constant reflection of the transformation of Goldman. The story of McDonald is similar in its descriptions of adoration, which guided McDonald and his colleagues' 'fight' for Lehman. The struggle to 'survive' and to get recognized on the trading floor is similar to Smith's description. However, whereas Smith was finally agonized by a general shift in the company culture, the struggle of McDonald focused on the course of the top-management, namely the personal behavior of Fuld and McGregory. Proud of his own time on the trading floor and the respective 'fights' of his colleagues and himself, the decline of Lehman was accompanied by feelings of sadness and anger. Finally, the case of Anne T. stands in contrast to the first two narrations. Here, to get recognized means to earn money, even in disregard to clients or the company in this course. Anne T. was attracted by the perceived thrill and toughness of a 'men's world'. Throughout the course, this initial adoration turned to cynicism and boredom. Consequently, the sole struggle for (more) money to get accepted and recognized became absurd. The following table sums up the main findings of analysis.

INSERT TABLE 1 ABOUT HERE

Our analysis allows for drawing two particular contributions to the study of institutional 
work. The first refers to the incorporation of emotions in this particular field of research. Although emotions have been recognized as a central element of organizational life (Fineman (2000)), little is known about the emotional aspects of institutional work (Creed et al. (2010); Voronov and Vince (2012)). When attending to those processes, the systematic conceptualization of the interrelatedness of emotions and social structure poses a particular challenge. Thus, framing emotions and emotional dynamics in relation to a person's social position is inherent to the notion of embedded agency as a key premise of the institutional work perspective (Battilana and D'Aunno (2009)). Our framework facilitates such a perspective and helps to grasp emotions as a constitutive element of institutions themselves (Scott (2008)). Thus, by looking at emotions that are associated with recognition and by understanding institutions as outcomes of struggle for recognition, the relational and collective dimension of emotions is particularly acknowledged. Specifically, Honneth's work endorses the importance to the argument that institutions evoke feelings and desires by shaping and challenging expectations of 'due' recognition. Over a lifetime and in interrelation with the social structure, a person develops particular desires for recognition; that is, he/she gains a sentiment for misrecognition. Such a perspective allows for looking at a specific dimension of the 'normative character of every day experiences' and for defining individuals primarily as 'normative beings' (Sayer $(2005,949)$ ). Focusing on recognition means turning towards the normative commitments of a person and indicates that questions and answers on 'good' and 'bad' might considerably drive the emotional dynamics and respective processes of institutional work. Similarly, from the perspective of the arguments presented here, organizations can be understood as sites, counterpart, and results of struggles for recognition, inevitably engaged in a person's attempts at building a valued identity and (self) respect. This way, and concerning Honneth's idea that respective patterns of recognition basically intersect nowadays' institutions, our framework also supports analytical attendance to the social embedment of institutions, particularly in terms of their normative fundamental of organizing. In doing so, it follows the plea to conceptualize institutions as 'doubly embedded, with an inherent micro-macro connection' (Hallet and Ventresca (2006, 227)). Thus, not least in times of heightened expectations towards the moral responsibility of organizations (Paine (2003)), we believe that research on institutional work would benefit from a stronger focus on the institutional effects of recognition and respective struggles.

Furthermore, when introducing our framework as a potential means to incorporate 
emotions in studies of institutional work, we have to highlight that 'recognition' runs counter to analytical dichotomies of emotion and cognition or rationality and irrationality (Sayer (2005)). Perceived (mis)recognition refers to both emotional and cognitive aspects as well as rational interests and putative irrational claims. Thus, some articulations of (mis)recognition can be exclusively felt as such on the basis of cognition and reason. Accordingly, Sayer (2005, 959) explains: 'When someone says that they 'have good reason to be angry', they [emotions] imply that someone has done something that objectively harms them, such as injuring them or slandering them.' Elaborating on recognition as a driver of institutional work thus frequently demands 'a more cognitive view of emotions' (Sayer $(2005,959)$ ) as a form of evaluative judgments about situations and processes. Similar to Voronov and Vince (2012), we thus propose that respective characteristics of a person's cognitive and emotional positioning towards an institution basically effect the engagement in institutional work. Our findings particularly indicate an interplay between positive and negative emotions and cognition on the one hand, and specific effects on institutional work on the other. Stories of Smith and McDonald show that a cognitive consideration of the author's positioning in and towards the institution was increasingly driven by decreased seducement and growing agony. These experiences drove their behaviors and actions in a sense of more strategic or reasoned attempts to engage in maintenance work. Also, the story of Anne T. suggests that positive emotions of seducement which overwhelmed her early career were increasingly absorbed by felt agony due to her increased capacity for a cognitive consideration of the formal and informal mechanisms of the business, which resulted in her decision to quit the job. Against this backdrop, we advocate a deeper investigation of the particular interplay between these elements and the respective outcomes for institutional work processes.

By introducing the notion of recognition, we see a second contribution for studying institutional work in the general entanglement with questions on the formation of subjectivity, identity, and respective forms of power and domination (Knights and Willmott (1989); Stavrakakis (2008)). As our analysis indicates too, persons are inevitably tied to recognition and respective forms of power and domination in order to develop a relation-toself and identity. This might specifically explain the stability of institutional arrangements, even in the case of perceived insufficiency and dysfunctionality of respective relations and institutions (Ekman (2013); Lok and Willmott (2014)). In contrast, and as we see from our autobiographies as well, aspirations towards identity and self-respect can particularly trigger 
the disruption and advancement of institutions and respective relations of power. In their study on care workers, Tomkins and Eatough (2014) sensitize for this possibility of rejection of recognition and scrutinizing of power structures, if the same undermines the efforts of identity work on the part of the addressees. In particular, the perspective on recognition suggests a more nuanced differentiation between the respective effects of a person's desires for material and non-material offers of recognition. Thus, our reading of Anne T.'s story points to the importance of monetary rewards in terms of recognition, while indicating at the same time that highly 'seductive' monetary rewards and respective offers of recognition might be insufficient for producing a positive relation-to-self over time or an acceptance of respective power relations, if one must sacrifice alternative notions of the self in the process. Similarly, Pratt (2000) in his study on Amway distributors shows that financial success with the organization is not inevitably decisive to engage in maintenance of the institution. However, recognition as an analytical category blurs boundaries between the rational - or calculative estimation of material rewards - on the one hand and the emotional assimilation of non-material appreciation on the other. In our view, the interplay of these two dimensions of recognition might be of particular relevance when investigating person's engagement in institutional work and mechanisms of domination and power. Thereby the mechanisms of seducement and agony referring to material and non-material recognition might considerably vary between institutions in world of finance and other contexts, like creative industries (Ekmann (2013)) or religious institutions (Creed et al. (2010)).

Again and more generally, a key question applies to the normative commitments of a person to one's own or another's valuable or 'recognizable' characteristics. Our analysis of the stories of Smith and McDonald clearly reveal such normative commitments towards a certain company culture, which informed respective expectations for the 'due' interaction of the company with clients, colleagues, and the authors themselves. Following Weiskopf and Willmott (2013), we suggest that such commitments allow for establishing 'ethical moments' pointing to an emerging relation-to-self that is partly independent from prevailing relations of power. Immediately addressing one's position in the world, such moments are often highly emotional and agonizing experiences. However, as Sayer pronounces: 'If we had no normative commitments, then it is hard to see why we would ever want to resist and how we would ever be shamed, because we would simply 'go with the flow', accepting whatever the pressure of the moment required' (Sayer $(2005,955)$ ). Against this backdrop, and as our 
reading of Smith's and McDonald's autobiographies suggests as well, we argue that such normative commitments bear considerable potential to drive behaviors and actions in opposition to prevailing power structures. This way, Honneth's writings emplace a kind of analytical reverse image to broaden the research on the stability of institutional orders and power structures due to the control of subjectivity (Alvesson and Willmott (2002); Lok and Willmott (2014); Stavrakakis (2008)). Thus, several pieces of advice for persons suffering from misrecognition (Creed et al. (2010); Ekmann (2013); Tomkins and Eatough (2014)) might include a more systematic elaboration of the factual and even subtle struggles for recognition taking place in the processes of institutional work every day. This points finally to the plea for a more critical institutional theory (Willmott (2011); Willmott (2015)). Our study highlights struggles for recognition and points to potentially 'ethical moments' as well as power structures. However, our main focus was on the factual reconstruction of respective struggles. Consequently, we cannot evaluate the struggles of recognition and respective institutional structures in terms of its emancipatory or regressive and subjugating potential. This way, our paper might be also understood as an invitation to further envelop the critical and normative claim of the theory of recognition for institutional theory and management and organization studies in general.

\section{References}

Alvesson, Mats and Hugh Willmott (2002), Identity Regulation as Organizational Control: Producing the Appropriate Individual, Journal of Management Studies 39 (5), 619644.

Anne T. (2010), Die Gier war grenzenlos. Eine deutsche Börsenhändlerin packt aus, Berlin: Ullstein.

Ashforth, Blake E. and Ronald H. Humphrey (1995), Emotion in the Workplace: A Reappraisal, Human Relations 48 (2), 97-124.

Battilana, Julie and Thomas D'Aunno (2009), Institutional Work and the Paradox of Embedded Agency, in Lawrence, Thomas B., Roy Suddaby and Bernard Leca (eds.), Institutional Work: Actors and Agency in Institutional Studies of Organizations, Cambridge, U.K.: Cambridge University Press, 31-58.

Boudens, Connie J. (2005), The Story of Work: A Narrative Analysis of Workplace Emotion, Organization Studies 26 (9), 1285-1306. 
Burawoy, Michael (1998), The Extended Case Method, Sociological Theory 16 (1), 4-33.

Cooke, Maeve (2006), Re-Representing the Good Society, Cambridge, Mass: MIT Press.

Creed, W. E. Douglas, Rich DeJordy and Jaco Lok (2010), Being the Change: Resolving Institutional Contradiction through Identity Work, Academy of Management Journal 53 (6), 1336-1364.

Creed, W. E. Douglas, Bryant A. Hudson, Gerardo A. Okhuysen and Kristin Smith-Crowe (2014), Swimming in a Sea of Shame: Incorporating Emotion into Explanations of Institutional Reproduction and Change, Academy of Management Review 39 (3), 275301.

Crouch, Colin (2011), The Strange Non-Death of Neoliberalism, Cambridge: Polity Press.

Czarniawska-Joerges, Barbara (1996), Autobiographical Acts and Organizational Identities, in Stephen A. Linstead, Robert Grafton Small and Paul Jeffcutt (eds.), Understanding Management, London: SAGE, 157-71.

Dukerich, Janet M., Roderick Kramer and Judi McLean Parks (1998), The Dark Side of Organizational Identification, in David A. Whetten and Paul C. Godfrey (eds.), Identity in Organizations. Building Theory through Conversation, Thousand Oaks, London, New Delhi: SAGE, 245-256.

Eisenhardt, Kathleen M. (1989), Building Theories from Case Study Research, Academy of Management Review 14 (4), 532-550.

Ekman, Susanne (2013), Fantasies about Work as Limitless Potential - How Managers and Employees Seduce Each Other through Dynamics of Mutual Recognition, Human Relations 66 (9), 1159-1181.

Elfenbein, Hillary A. (2007), Emotion in Organizations, The Academy of Management Annals 1 (1), 315-386.

Fineman, Stephen (2002). Emotions in Organizations. London: SAGE.

Fleming, Peter and Andrew Spicer (2007), Contesting the Corporation: Struggle, Power, and Resistance in Organizations. Cambridge: Cambridge University Press.

Fraser, Nancy and Axel Honneth (2003), Umverteilung oder Anerkennung? Frankfurt/Main: Suhrkamp.

Greenwood, Royston and Roy Suddaby (2006), Institutional Entrepreneurship in Mature Fields: The Big Five Accounting Firms, Academy of Management Journal 49 (1), 2748. 
Grover, Steven L. (2013), Unraveling Respect in Organization Studies, Human Relations $67(1), 27-51$.

Hallet, Tim and Marc J. Ventresca (2006), Inhabited Institutions: Social interactions and organizational forms in Gouldner's Patterns of Industrial Bureaucracy. Theory and Society, 35, 213-236.

Hardy, Cynthia and Steve Maguire (2008) Institutional Entrepreneurship, in Royston Greenwood, Christine Oliver, Kerstin Sahlin-Andersson and Roy Suddaby (eds.), The SAGE Handbook of Organizational Institutionalism, London: SAGE, 198-217.

Honneth, Axel (1996), The Struggle for Recognition, Cambridge: Polity Press.

Honneth, Axel (1997), Recognition and Moral Obligation, Social research 64 (1), 16-35.

Honneth, Axel (2010), Recognition as Ideology, in Bert van den Brink and David Owen (eds.), Recognition and Power. Axel Honneth and the Tradition of Critical Social Theory, Cambridge: Cambridge University Press, 323-347.

Islam, Gazi (2012), Recognition, Reification and Practices of Forgetting: Ethical Implications of Human Resource Management, Journal of Business Ethics 111(1), 3748.

Islam, Gazi (2013), Recognizing Employees: Reification, Dignity and Promoting Care in Management, Cross Cultural Management: An International Journal 20(2), 235-250.

Jacobs, Mark D. (2012), Financial Crises as Symbols and Rituals, in Karin Knorr-Cetina and Alex Preda (eds.), The Oxford Handbook of the Sociology of Finance, Oxford: Oxford University Press, 376-392.

Knights, David and Hugh Willmott (1989), Power and Subjectivity at Work: From Degradation to Subjugation in Social Relations, Sociology 23 (4), 535-558.

Kreiner, Glen E. and Blake E. Ashforth (2004), Evidence Toward an Expanded Model of Organizational Identification, Journal of Organizational Behavior 25 (1), 1-27.

Lawrence, Thomas B., Roy Suddaby and Bernard Leca (2009), Introduction: Theorizing and Studying Institutional Work, in Thomas B. Lawrence and Bernard Leca (eds.), Institutional work. Actors and Agency in Institutional Studies of Organizations, Cambridge: Cambridge University Press, 1-27.

Lawrence, Thomas B., Roy Suddaby and Bernard Leca (2011), Institutional work: Refocusing Institutional Studies of Organization, Journal of Management Inquiry 20, $52-58$. 
Lawrence, Thomas B. (2008), Power, Institutions and Organizations, in Royston Greenwood, Christine Oliver, Kerstin Sahlin-Andersson and Roy Suddaby (eds.), The SAGE Handbook of Organizational Institutionalism, London: SAGE, 170-197.

Lok, Jaco and Hugh Willmott (2014), Identities and Identification in Organizations: Dynamics of Antipathy, Deadlock, and Alliance, Journal of Management Inquiry 23 (3), 215-230.

MacKenzie, Donald (2009), Material Markets: How Economic Agents are Constructed, Oxford: Oxford University Press.

McDonald, Lawrence G. and Patrick Robinson (2009), A Colossal Failure of Common Sense: The Inside Story of the Collapse of Lehman Brothers, New York: Three Rivers Press.

Paine, Lynn S. (2003), Value Shift. Why Companies Must Merge Social and Financial Imperatives to Achieve Superior Performance, New York, Chicago, San Francisco et al.: McGraw-Hill.

Plummer, Ken (2001), The Call of Life Stories in Ethnographic Research, in Paul Atkinson, Amanda Coffey, Sara Delamont, John Lofland and Lyn Lofland (eds.), Handbook of Ethnography, London: SAGE, 395-406.

Pratt, Michael G., (2000), The Good, the Bad, and the Ambivalent: Managing Identification Among Amway Distributors, Administrative Science Quarterly 45 (3), 456-493.

Saldana, Johnny (2012), The Coding Manual for Qualitative Researchers, London: SAGE. Sayer, Andrew (2005), Class, Moral Worth and Recognition, Sociology 39 (5), 947-963.

Sayer, Andrew (2007), Dignity at Work: Broadening the Agenda, Organization 14 (4), 565581.

Scott, W. Richard (2008), Institutions and Organizations: Ideas and Interests, Thousand Oaks: SAGE.

Smith, Greg (2012), Why I Left Goldman Sachs. A Wall Street Story, New York and Boston: Grand Central Publishing.

Stavrakakis, Yannis (2008), Subjectivity and the Organized Other: Between Symbolic Authority and Fantasmatic Enjoyment, Organization Studies 29 (7), 1037-1056.

Tomkins, Leah and Virginia Eatough (2014), Stop 'Helping' Me! Identity, Recognition and Agency in the Nexus of Work and Care, Organization 21 (1), 3-21.

Van den Brink, Bert and David Owen (2010), Recognition and Power: Axel Honneth and the 
Tradition of Critical Social Theory, Cambridge: Cambridge University Press.

Voronov, Maxim and Russ Vince (2012), Integrating Emotions into the Analysis of Institutional Work, Academy of Management Review 37 (1), 58-81.

Watson, Tony J. (2009), Narrative, Life Story and Manager Identity: A Case Study in Autobiographical Identity Work, Human Relations 62 (3), 425-452.

Weiskopf, Richard and Hugh Willmott (2013), Ethics as Critical Practice: The 'Pentagon Papers', Deciding Responsibility, Truth-Telling, and the Unsettling of Organizational Morality, Organization Studies 34 (4), 469-493.

Willmott, Hugh (2011), 'Institutional Work' for what? Problems and Prospects of Institutional Theory, Journal of Management Inquiry 20 (1), 67-72.

Willmott, Hugh (2015), Why Institutional Theory Cannot be Critical, Journal of Management Inquiry 24(1), 105-111. 
Table 1: Summary of the cases

\begin{tabular}{|c|c|c|c|c|c|}
\hline $\begin{array}{l}\text { "I felt at home" } \\
\text { - Greg Smith }\end{array}$ & $\begin{array}{l}\text { "The boot camp" } \\
\text { Struggles: } \\
\text { - Representative } \\
\text { of company } \\
\text { principles } \\
\text { - Acceptance on } \\
\text { the trading floor } \\
\text { Emotions: } \\
\text { - Enjoyment, Pride, } \\
\text { Thrill }\end{array}$ & $\begin{array}{r}\text { Strugg } \\
-\quad \text { Suc } \\
\text { trad }\end{array}$ & $\begin{array}{l}\text { Struggles: } \\
\text { - Success on the } \\
\text { trading floor }\end{array}$ & $\begin{array}{l}\text { Struggles: } \\
\text { - Keeping the company } \\
\text { principles alive } \\
\text { - Dealing with } \\
\text { disregard } \\
\text { Emotions: } \\
\text { - Discomfort, Shame }\end{array}$ & $\begin{array}{l}\text { exit \& } \\
\text { NYT } \\
\text { article }\end{array}$ \\
\hline $\begin{array}{l}\text { "On the } \\
\text { gundeck of the } \\
\text { ship" - } \\
\text { Lawrence G. } \\
\text { McDonald }\end{array}$ & $\begin{array}{l}\text { Struggles: } \\
\text { - Make Wall Street } \\
\text { - Acceptance on the } \\
\text { floor }\end{array}$ & ding & $\begin{array}{l}\text { Struggl } \\
\text { - Keepir } \\
\text { - Dealin }\end{array}$ & $\begin{array}{l}\text { Lehman alive } \\
\text { with disrespect }\end{array}$ & layoff \\
\hline $\begin{array}{l}\text { "It's me, the } \\
\text { queen of } \\
\text { money" - Anne } \\
\text { T. }\end{array}$ & \multicolumn{2}{|c|}{$\begin{array}{l}\text { Struggles: } \\
\text { - 'Join the party' } \\
\text { - Acceptance on the trading } \\
\text { floor }\end{array}$} & $\begin{array}{l}\text { Struggl } \\
\text { - Succe } \\
\text { - Succe }\end{array}$ & $\begin{array}{l}\text { on the trading floor } \\
\text { in dealing with clients }\end{array}$ & exit \\
\hline
\end{tabular}

